\title{
Comparative Analysis Between Fly Ash Geopolymer and Reactive Ultra-Fine Fly Ash Geopolymer
}

\author{
Wei-Ting Lin ${ }^{1, *}$, Kae-Long Lin ${ }^{2}$, Kinga Korniejenko ${ }^{3}$, Lukáš Fiala ${ }^{4}$ \\ ${ }^{1}$ Department of Civil Engineering, National Ilan University, Yilan, Taiwan \\ ${ }^{2}$ Department of Environmental Engineering, National Ilan University, Yilan, Taiwan \\ ${ }^{3}$ Institute of Materials Engineering, Faculty of Materials Engineering and Physics, \\ Cracow University of Technology, Kraków, Poland \\ ${ }^{4}$ Department of Materials Engineering and Chemistry, Faculty of Civil Engineering, \\ Czech Technical University in Prague, Prague, Czech Republic \\ Received 09 February 2021; received in revised form 06 April 2021; accepted 07 April 2021 \\ DOI: https://doi.org/10.46604/ijeti.2021.7129
}

\begin{abstract}
This study investigates novel geopolymers by combining Reactive Ultra-fine Fly Ash (RUFA) with 4M sodium hydroxide as an alkali activator. Comparing with general fly ash geopolymers, RUFA geopolymer pastes are characterized in terms of compressive strength, microstructure, and crystalline phases. The RUFA geopolymer is successfully obtained as alumina-silicate bonding materials with the same properties as the general fly ash-based geopolymer. The high compressive strength of the RUFA-based geopolymer samples (13.33 MPa) can be attributed primarily to Ca-based alumino-silicate hydration products and Na-based alumino-silicate complexes. This research presents an innovative application for geopolymers using RUFA. In the follow-up study, the influence of synthesis and concentration of alkali activator can be considered in RUFA-based geopolymers.
\end{abstract}

Keywords: reactive ultra-fine fly ash, alkali activator, spherical particles, microscopic properties, amorphous

\section{Introduction}

\subsection{Background and motivation}

The explosion of the world's population in the past few decades has created the problem of housing shortages. Most buildings are built by using cement, creating massive amounts of $\mathrm{CO}_{2}$ (the leading culprit of the greenhouse effect) [1-3]. Greenhouse gases retain the energy by absorbing infrared radiation and thereby cause the gradual temperature rise at the earth's surface, which accelerates global warming. To mitigate the greenhouse effect, governments should focus on devising effective measures to reduce greenhouse gas emissions. Cutting down on cement use would not only reduce $\mathrm{CO}_{2}$ emissions and slow down the greenhouse effect, but also promote energy conservation. Portland cement is one of the primary materials used in construction. Approximately 3 billion tons of Portland cement is produced every year [4]. However, for every ton of Portland cement produced, 0.55 tons of $\mathrm{CO}_{2}$ is created via chemical reactions and 0.39 tons of $\mathrm{CO}$ is generated by combustion and fuel emissions during the production process, which adds up to approximately 0.94 tons of $\mathrm{CO}_{2}$ [5]. An investigation report in 2000 [6-7] revealed that an average of $0.87 \mathrm{~kg}$ of $\mathrm{CO}_{2}$ is emitted for every kilogram of cement produced and that the cement

* Corresponding author. E-mail address: wtlin@ niu.edu.tw Tel.: +886-3-9137567; Fax: +886-3-9360125 
manufacturing industry contributes to $7 \%$ of global $\mathrm{CO}_{2}$ emissions [8]. The report further forecasted that the global demand for Portland will double to 6 billion tons per year within the next 40 years [9]. Therefore, the use of suitable materials as an alternative to cement in construction materials is an important research issue.

\subsection{Literature survey}

Geopolymer is one kind of low carbon emission green composites. It is formed through the process of geopolymerization after alkaline solution reacts with such industrial by-products or wastes. Geopolymer is an inorganic alumino-silicate compound and it is usually produced from conventional pulverized coal fly ash. An emerging technology for stabilizing the frame-like polymerization structure in geopolymer can help with energy saving and carbon reduction [10]. This new generation of green materials may also replace ordinary cement and concrete in the future. Geopolymer is composed of $\mathrm{SiO}_{4}$ and $\mathrm{AlO}_{4}$ tetrahedrons sharing oxygen atoms to form a closed frame structure of Si-O-Al, which is similar to Zeolite. Its hardening mechanism is similar to that of conventional cement. It is the inorganic polymerization between the particles of the system colloid. The hardening time is about 1.5 to 2.0 hours at room temperature, which is one kind of early-strength material [10-11].

The hardening mechanism of geopolymer is different from conventional cement in that the cement is hardened as a hydration bond, while the geopolymer is a chemical bond. At this stage, the development of geopolymer into a new generation of environmentally friendly materials has considerable real potential. Geopolymer should be multi-functional materials and have better properties than traditional cement-based materials, including rheological, mechanical, thermal properties, process properties, durability, and so on [12-13]. It has been already proven that some materials properties of geopolymer composites are comparable or even better than those of the traditional cementitious materials, which are another positive finding in addition to the environmental aspect. Albitar et al. [14] concluded that geopolymer concrete are more chemically stable and superior to conventional concrete in an acidic environment, and exhibit lower deterioration of mechanical properties under chemical attacks.

An increasing burden on the environment caused by industrial activities (involving non-negligible contribution of cement production) creates a demand for seeking for reliable alternative non-cement construction materials possessing comparable properties with cementitious materials. There are various ways of preparation of promising non-cement materials which are based on partial replacement of cement by other eco-friendlier constituents. Non-cement materials produced by using various precursors and alkalis, or blending of materials, can react together and form a solid matrix of reasonable mechanical performance. The geopolymers made with waste materials, such as fly ash and ground granulated blast furnace slag, are attracting widespread attention as a green alternative to Portland cement [15-16]. These materials have also been widely adopted in the construction industry due to their excellent mechanical properties and durability [17-18]. Reactive Ultra-fine Fly Ash (RUFA) is an industrial by-product from thermal power plants heated to $1300^{\circ} \mathrm{C}$, with the same chemical composition as conventional fly ash (heated from 900 to $1100^{\circ} \mathrm{C}$ ) but smaller spherical particles ranging in size from $0.1 \mu \mathrm{m}$ to $10 \mu \mathrm{m}$ [19]. The large surface area provided by the superfine particles greatly enhances pozzolanic activity, sufficient for the partial replacement of Portland cement [19].

\subsection{Purpose and organization}

RUFA has spherical particles of an amorphous structure and is a new industrial by-product from thermal power plants. The chemical composition of RUFA is similar to conventional pulverized coal fly ash and it is suitable for manufacturing geopolymeric binder which can occur under curing conditions at elevated temperatures between 50 to $80^{\circ} \mathrm{C}$ as well as considered a cleaner process due to much lower $\mathrm{CO}_{2}$ emission. In this study, we examine the feasibility of creating RUFA-based geopolymers using sodium hydroxide as an alkali activator. It also presents a comparison of geopolymers made 
on the conventional fly ash and RUFA. Polymer specimens are characterized in terms of chemical composition, compressive strength, and microstructure. Fig. 1 shows the flow chart for the RUFA geopolymer research approach. The process consists of five steps:

(1) To analyze the physical and chemical analysis of RUFA particles and traditional fly ash;

(2) To formulate a suitable mix design of RUFA geopolymer;

(3) To cast the specimens and conduct the testing preparation;

(4) To use evaluation tests, including X-ray Diffraction (XRD) analysis, compressive strength test, Scanning Electron Microscopy (SEM) observations, Energy Dispersive Spectroscopy (EDS) analysis, and Thermogravimetric and Differential Thermal Analysis (TG-DTA);

(5) To evaluate the feasibility of RUFA geopolymer.

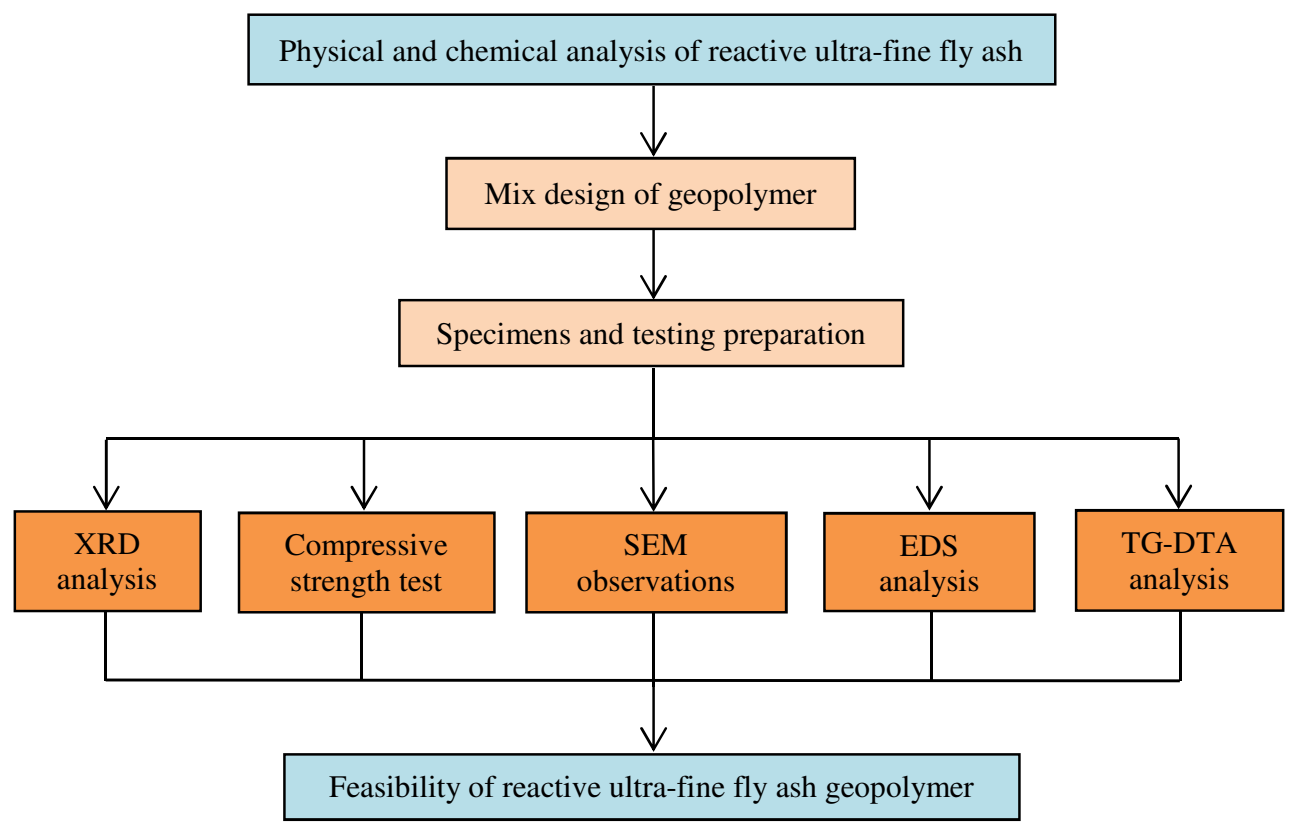

Fig. 1 Creative RUFA geopolymer research methodology

\section{Test Methods}

\subsection{Materials}

The RUFA used in this study is obtained from a power plant in Taiwan (TRIAXIS Corporation). The light gray RUFA comprises spherical particles ranging in size from $0.1 \mu \mathrm{m}$ to $5.0 \mu \mathrm{m}$, most of which are amorphous phases, as indicated by a broad hump in XRD patterns at $2 \theta$ between $20^{\circ}$ and $35^{\circ}$ [19]. The specific surface area of RUFA is $3380 \mathrm{~m}^{2} / \mathrm{kg}$ and the specific gravity is 2.67, respectively. The SEM photo and EDS result of the spherical particles of RUFA are shown in Fig. 2 and Table 1 , respectively.

The composition of the RUFA is as follows: silicon dioxide (49.11\%), aluminum oxide (28.07 \%), and calcium oxide $(8.84 \%)$ by the results using X-ray fluorescence. The primary oxide content in RUFA is similar to that of general class F fly ash $\left(\mathrm{SiO}_{2}+\mathrm{Al}_{2} \mathrm{O}_{3}+\mathrm{Fe}_{2} \mathrm{O}_{3} \geq 75\right.$ wt. \%). At $28^{\text {th }}$ days, the pozzolanic strength activity index of RUFA $(107 \%)$ is higher than that of general fly ash (72-83\%) [19]. Sodium hydroxide $(\mathrm{NaOH})$ beads of 98 wt.\% purity are mixed with deionized water at a concentration of 4.0 $\mathrm{M}$ for use as an alkaline activator. 


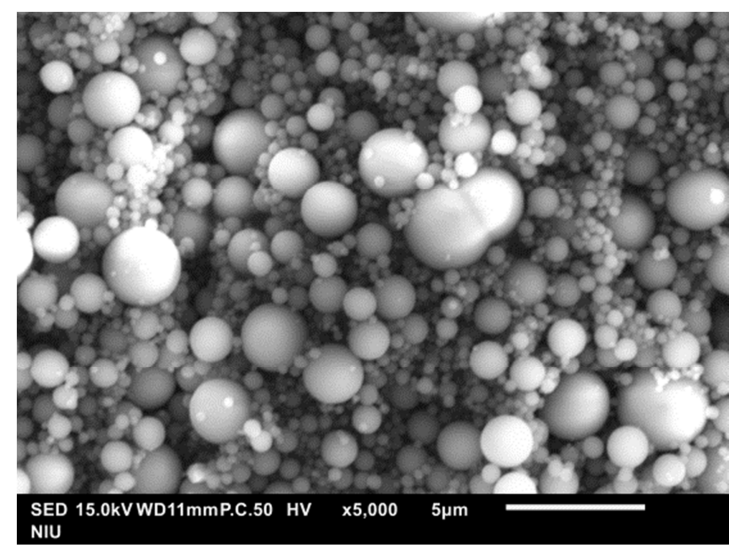

Fig. 2 SEM image of RUFA particles $(5,000 x)$

Table 1 EDS results of RUFA particles

\begin{tabular}{|c|c|c|}
\hline Element & Weight \% & Atomic \% \\
\hline $\mathrm{C}$ & 13.38 & 20.81 \\
\hline $\mathrm{O}$ & 53.56 & 62.51 \\
\hline $\mathrm{Ca}$ & 27.23 & 12.69 \\
\hline $\mathrm{Si}$ & 2.93 & 1.95 \\
\hline $\mathrm{Mg}$ & 1.07 & 0.82 \\
\hline $\mathrm{Al}$ & 1.45 & 1.00 \\
\hline $\mathrm{S}$ & 0.38 & 0.22 \\
\hline Total & 100 & 100 \\
\hline
\end{tabular}

\subsection{Mix design, specimens, and test methods}

The composition of the RUFA-based geopolymer pastes is RUFA and sodium hydroxide. RUFA geopolymer specimens are prepared by mixing RUFA with 4.0 M NaOH solution (160g of $\mathrm{NaOH}$ powders are added in $1000 \mathrm{ml}$ deionized water) at a constant liquid/binder ratio of 0.30 for $5 \mathrm{~min}$ in paste mixing process. The fresh pastes are immediately poured into cubic molds $(50 \times 50 \times 50 \mathrm{~mm})$ and shaken on a vibration table for $2 \mathrm{~min}$ to remove entrained air, and then held at $50^{\circ} \mathrm{C}$ for $24 \mathrm{~h}$ using the oven. After initial curing, the specimens are removed from the molds to continue curing at room temperature until testing.

Compressive strength tests are conducted at curing ages of $7^{\text {th }}, 14^{\text {th }}$, and $28^{\text {th }}$ days, in accordance with ASTM C109 standards. The compressive strengths in this study are averaged from five specimens. Following compression testing, the specimens are ground into powders for subsequent analysis via SEM, EDS, XRD and thermal analysis. SEM and EDS examinations are performed at $7^{\text {th }}$ and $28^{\text {th }}$ days, in accordance with ASTM C1723 standards. TG-DTA is conducted at a curing age of $28^{\text {th }}$ days at temperatures ranging from $20^{\circ} \mathrm{C}$ to $1000^{\circ} \mathrm{C}$ under a heating rate was $10^{\circ} \mathrm{C} / \mathrm{min}$. XRD analysis is scanning at $2 \theta$ from range for $10^{\circ}$ to $65^{\circ}$ at the age of $28^{\text {th }}$ days in accordance with ASTM C 1365 .

\section{Results and Discussion}

\subsection{Feasibility of RUFA and traditional fly ash geopolymer in paste mixture}

The liquid/binder ratio of traditional fly ash-based geopolymer mixed with the sodium hydroxide as alkaline activator is between 0.4 and 0.6 . For a lower liquid/binder ratio of 0.3 , a mixed activator of sodium hydroxide and sodium silicate is suitable as an alkali activator, but its workability will be considerably reduced. The liquid/binder ratio of traditional fly ash-based geopolymer is too low to make it mix into geopolymer pastes. At a liquid/binder ratio of 0.30 in RUFA geopolymer, the geopolymer pastes can be evenly mixed and the mix is very viscous when the mold is lifted away from the paste as shown in Fig. 3(a). As shown in Fig. 3(b), the geopolymer pastes are immediately dropped at the table 25 times in 15 sec in accordance with the standard of ASTM C1437. RUFA geopolymer pastes are performed better fluidity as the flowability is between 90 to 
$100 \%$. The spherical RUFA particles have good water retention and cohesion as well as the increased lubricant effect. It is mentioned that the fluidity of RUFA geopolymer is improved [19]. When RUFA reacts with alkali activator forming geopolymers, its finer surface gets reactivated reaction and amorphous reaction products. Higher pozzolanic strength activity index and finer particles of RUFA [19] benefit the RUFA geopolymer pastes to be evenly mixed. This is verified that it is feasible for RUFA to mix $\mathrm{NaOH}$ as the geopolymer pastes.

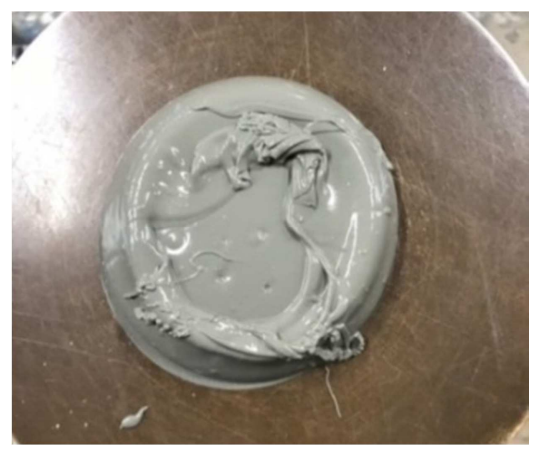

(a) Lift the mold away from the paste

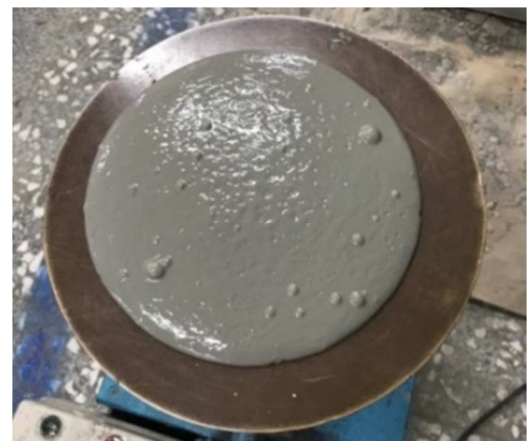

(b) Immediately drop the table 25 times in $15 \mathrm{sec}$

Fig. 3 Appearance of RUFA geopolymer in paste mixing process

\subsection{Compressive strength and XRD patterns}

As shown in Fig. 4, the compressive strength increases from 6.17 MPa at $7^{\text {th }}$ days and $10.07 \mathrm{MPa}$ at $14^{\text {th }}$ days to 13.33 $\mathrm{MPa}$ at $28^{\text {th }}$ days. Note that the strength at $28^{\text {th }}$ days is close to that of geopolymer made using traditional fly ash with $4 \mathrm{M}$ $\mathrm{NaOH}$ as activator (15 MPa) [20-21]. The increase in strength is proportional to the quantity of alumino-silicates provided from the RUFA. RUFA contains large quantities of $\mathrm{Al}(28 \%)$ and $\mathrm{Si}$ (49\%), which react with $\mathrm{NaOH}$ in geopolymer (general fly ash contains the quantities of $\mathrm{Al}(21 \%)$ and $\mathrm{Si}(48 \%))$. We also infer trace quantities of calcium silicate hydrates (C-S-H) and sodium alumino silicate (N-A-S). As shown in Fig. 5, $\mathrm{OH}^{-}$ions from the alkaline solution catalyze the reaction process, which promotes the dissolution of $\mathrm{Si}^{4+}$ and $\mathrm{Al}^{3+}$ ions from the RUFA. XRD peaks indicative of Tobermorite $\left[\mathrm{CaSiO}(\mathrm{OH})_{2}-4 \mathrm{H}_{2} \mathrm{O}\right]$, Pezzottaite $\left(\mathrm{CsAl}_{2} \mathrm{Si}_{6} \mathrm{O}_{18}\right)$, and Hedenbergite $\left(\mathrm{CaFeSi}_{2} \mathrm{O}_{5}\right)$ reveal the formation of sodium alumino-silicate hydrate $(\mathrm{N}-\mathrm{A}-\mathrm{S}-\mathrm{H})$ and/or C-S-H gels. The formation of zeolite phases of sodium alumino-silicate and silica-rich can be attributed to the high solubility of silica and sodium in the alkaline solution under heat curing conditions [22]. We observe little difference between the diffractograms of the raw RUFA and RUFA-based geopolymers. This leads us to conclude that the geopolymers have a geopolymerisation form an amorphous to granular semi-crystalline structure, which is consistence with the previous study [23].

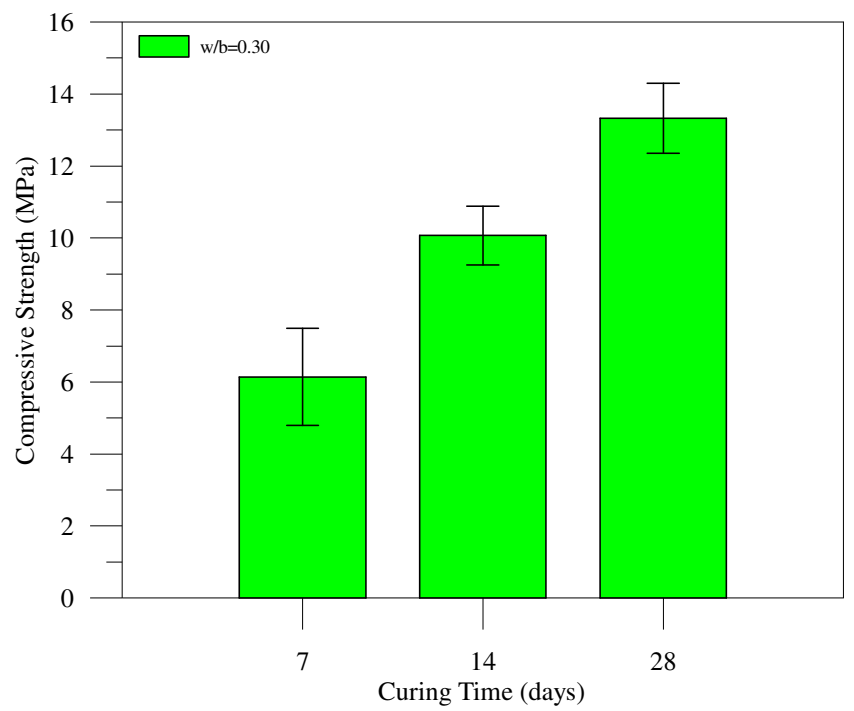

Fig. 4 Histogram showing compressive strength of specimens as a function of time 


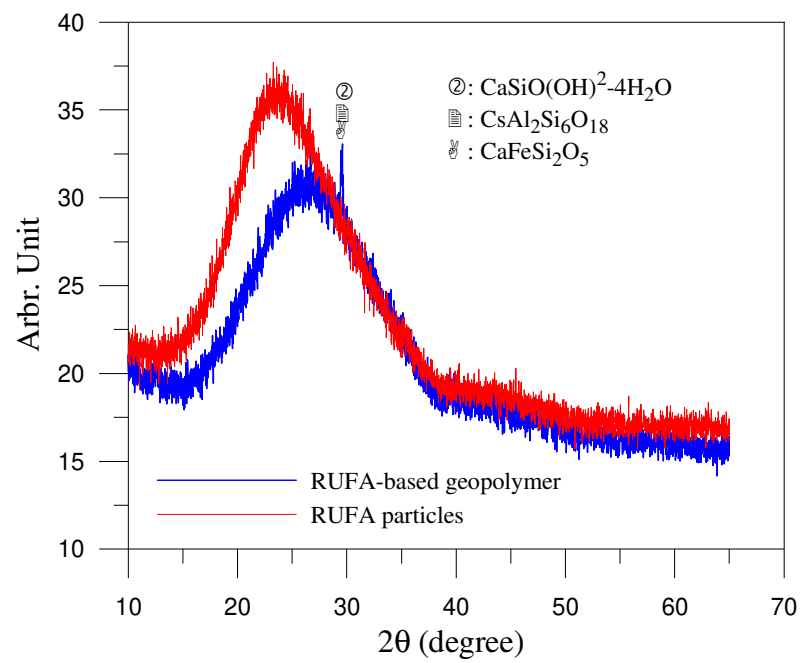

Fig. 5 XRD patterns of raw RUFA and RUFA-based geopolymer at $28^{\text {th }}$ days

\subsection{SEM and EDS analysis}

Hitachi S-4100 field emission electron microscope, which has a maximum magnification rate of 100,000, is used for SEM. This instrument uses an electron gun that shoots a beam of electrons. When the electron beam hits the surface of cement-based materials, it produces signals that are transmitted to a cathode ray tube via a signal amplifier and then displayed on a monitor screen, which allows the observation of microscopic crystal phases on the surface of the RUFA geopolymer. By adjusting the magnification rate and moving around the specimen, pictures of the desired microscopic crystal phases can be taken.

Fig. 6 illustrates the microscopic properties of the proposed RUFA-based geopolymer, as follows: (a) SEM image of raw RUFA; (b) SEM photo of paste at $7^{\text {th }}$ days; (c) SEM photo of paste at $28^{\text {th }}$ days. The paste consisted primarily of aluminosilicate gel or geopolymer paste with unreacted RUFA particles. The quantity of geopolymerisation at $28^{\text {th }}$ days is far higher than at $7^{\text {th }}$ days, which may account for the continual increase in compressive strength over that period. The reaction of RUFA with $\mathrm{NaOH}$ solution leads gradually to the formation of C-S-H, C-A-S-H, and N-A-S-H gels, which modifies the microstructure of the paste. RUFA geopolymer pastes are presented with multiple unreacted particles. It clearly shows that the inhomogeneous glass-like pastes of the amorphous aluminosilicate gel and the pastes are full of loosely structured RUFA grains of different sizes. This can be expected that if the $\mathrm{NaOH}$ content increases, the degree of reaction taking place in a geopolymer forming paste increases. It indicates that it needs more alkali activator with a higher Molar concentration of $\mathrm{NaOH}$ to enhance the polymerization process.

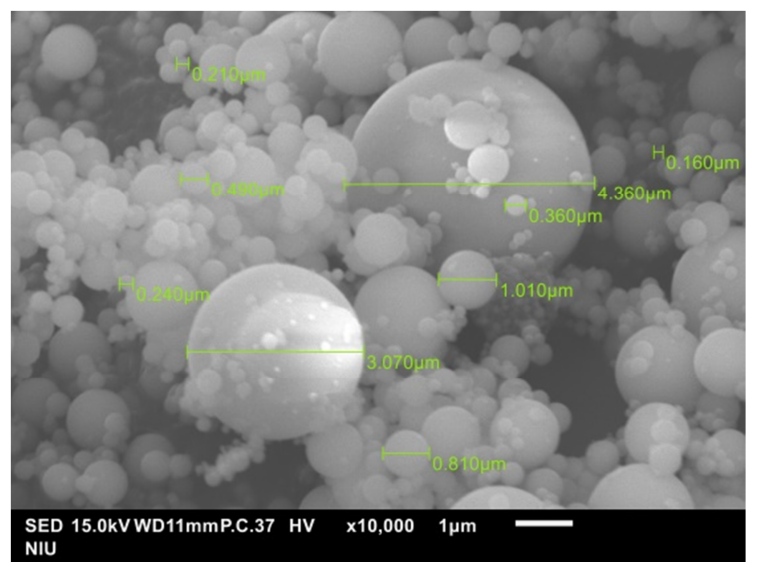

(a) SEM image of raw RUFA $(10,000 x)$

Fig. 6 Microscopic properties of RUFA-based geopolymer 


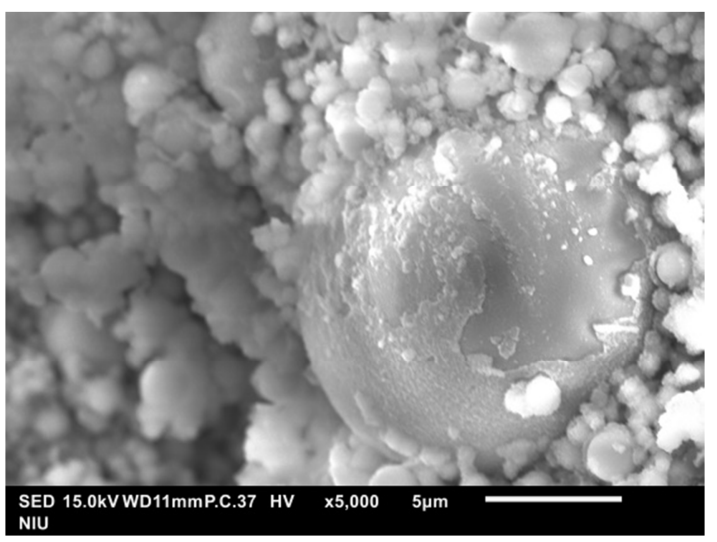

(b) SEM image and EDS results of paste at $7^{\text {th }}$ days $(5,000 \mathrm{x})$

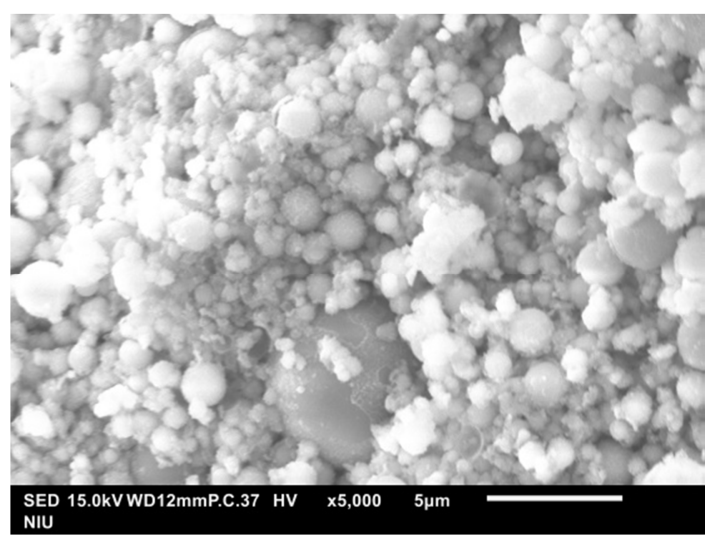

(c) SEM image and EDS results of paste at $28^{\text {th }}$ days $(5,000 \mathrm{x})$

Fig. 6 Microscopic properties of RUFA-based geopolymer (continued)

The elements analyzed by EDS mainly include $\mathrm{Si}, \mathrm{Al}, \mathrm{Na}, \mathrm{Ca}$ and $\mathrm{O}$ as shown in Tables 2 and 3 . The EDS results from $7^{\text {th }}$ to $28^{\text {th }}$ days reveal the slight gradual decrease in the Na content (from $4.46 \%$ to $4.35 \%$ ) as well as gradual increases in the $\mathrm{Si} / \mathrm{Al}$ ratio (from 2.82 to 3.23 ) and $\mathrm{Ca} / \mathrm{Si}$ ratio (from 0.27 to 0.31 ). The gradual increase in compressive strength can be attributed to the formation of Si-O-Si bonds, which are stronger than Si-O-Al bonds [24-25] and consistent with the XRD results. The previous study [26] reported that the dissolution speed of silicate bonds was faster than that of aluminum bonds; however, the geopolymerization speed of aluminum bonds was faster than that of silicate bonds. It also confirmed that the decrease of the $\mathrm{Si} / \mathrm{Al}$ ratio may be an indication of the process of geopolymerization [24, 26]. It also showed that gel mostly consists of the phases containing Na-Si-Al bonds and the formation of an alumino-silicate-activated gel by polymerization throughout the surface of the RUFA particles as shown in Figs. 6(b) and 6(c).

Table 2 EDS analysis of RUFA pastes at the age of $7^{\text {th }}$ days

\begin{tabular}{|c|c|c|}
\hline Element & Weight \% & Atomic \% \\
\hline $\mathrm{O}$ & 57.83 & 71.52 \\
\hline $\mathrm{Fe}$ & 2.68 & 0.95 \\
\hline $\mathrm{Na}$ & 4.46 & 3.84 \\
\hline $\mathrm{Al}$ & 6.83 & 5.01 \\
\hline $\mathrm{Si}$ & 19.25 & 13.56 \\
\hline $\mathrm{Ca}$ & 5.26 & 2.60 \\
\hline $\mathrm{Mg}$ & 2.14 & 1.75 \\
\hline $\mathrm{K}$ & 1.54 & 0.78 \\
\hline Total & 100 & 100 \\
\hline
\end{tabular}

Table 3 EDS analysis of RUFA pastes at the age of $28^{\text {th }}$ days

\begin{tabular}{|c|c|c|}
\hline Element & Weight \% & Atomic \% \\
\hline $\mathrm{O}$ & 56.69 & 70.67 \\
\hline $\mathrm{Fe}$ & 2.88 & 1.03 \\
\hline $\mathrm{Na}$ & 4.35 & 3.77 \\
\hline $\mathrm{Al}$ & 7.19 & 5.32 \\
\hline $\mathrm{Si}$ & 19.13 & 13.59 \\
\hline $\mathrm{Ca}$ & 5.93 & 2.95 \\
\hline $\mathrm{Mg}$ & 2.32 & 1.90 \\
\hline $\mathrm{K}$ & 1.52 & 0.77 \\
\hline Total & 100 & 100 \\
\hline
\end{tabular}

\subsection{TG-DTA results}

In this investigation, Thermogravimetry (TG) analysis is studied in terms of the weight-loss percentage as an index to define the compositions or formations. The Derivative Thermogravimetry (DTG) curves in Fig. 7 reveals an obvious decrease in mass (3.3 wt. \%) as the temperature of the specimens is increased to $200^{\circ} \mathrm{C}$. The mass decreases by a further $2.3 \mathrm{wt} . \%$ as the 
temperature is increased from $200^{\circ} \mathrm{C}$ to $650^{\circ} \mathrm{C}$, which indicates the analyzed bonded water of the $\mathrm{Ca}(\mathrm{OH})_{2}$ phase. A small drop between $200^{\circ} \mathrm{C}$ to $400^{\circ} \mathrm{C}$ has found in the DTG curve, which is corresponded to dehydration of C-A-S-H and C-S-H pastes [27-28]. The combination of $\mathrm{NaOH}$ and $\mathrm{Ca}(\mathrm{OH})_{2}$ activates the compressive strength development of the RUFA geopolymer. The TG curve remains steady after $650^{\circ} \mathrm{C}$ due to the swelling of the high silicate secondary phases [29]. The DTA curves reveal the transformation of amorphous aluminum phosphate phase into crystal phases (e.g. tridymite-like molecular structure) at approximately $870{ }^{\circ} \mathrm{C}$. Note that the same phenomenon is observed in geopolymer based on general/traditional fly ash [30]. The DTA curve also reveals that the reaction is endothermic between $300^{\circ} \mathrm{C}$ and $1200^{\circ} \mathrm{C}$, due to the sintering of high silicate secondary phases and extreme densification of the geopolymer pastes [29]. In addition, the loss in weight between $100^{\circ} \mathrm{C}$ and $700^{\circ} \mathrm{C}$ from the DTG curve could be due to structurally bonded water in the N-A-S-H gel, which is consistent with the results of the SEM and EDS analysis. It is also an indirect measure of the geopolymerization reaction [31]. It is also revealed that N-A-S-H and C-A-S-H gels prevail in high silicon and aluminum systems in RUFA geopolymer. The compressive strengths at the early stage ( $7^{\text {th }}$ to $28^{\text {th }}$ days) indicate a very promising performance to be an innovative application in green cementless composites.
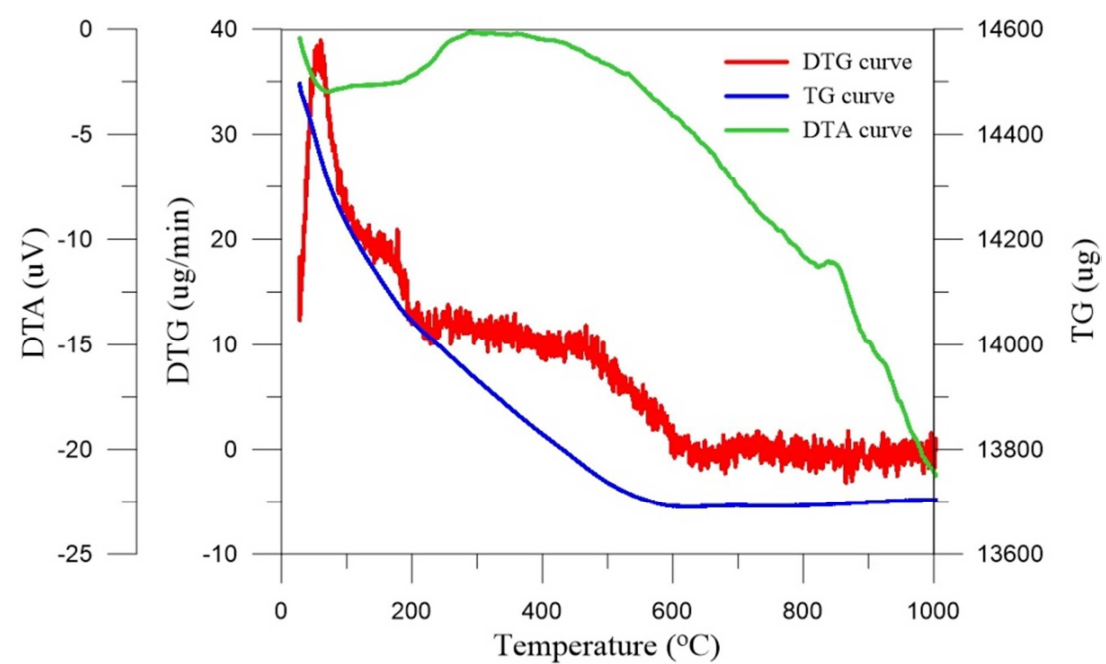

Fig. 7 DTG, DTA, and TG curves at $28^{\text {th }}$ days

\section{Conclusions}

This study reported on a RUFA-based geopolymer created by using 4-M NaOH solution as an activator. The high compressive strength of the proposed geopolymer (13.33 $\mathrm{MPa}$ at $28^{\text {th }}$ days) was attributed to the formation of hydration products (calcium- and sodium-based aluminosilicate hydration products). EDS results revealed gradual increases in the $\mathrm{Si} / \mathrm{Al}$ ratio and $\mathrm{Ca} / \mathrm{Si}$ ratio over time. Nonetheless, the microstructure presented aluminosilicate gel and unreacted RUFA particles at $28^{\text {th }}$ days. The concentration of the $\mathrm{NaOH}$ solution was shown to have a profound effect on strength development and the densification of the geopolymer in future research.

\section{Acknowledgements}

The RUFA provided by the TRIAXIS CORPORATION (www.triaxis.com.tw) is gratefully acknowledged. This work was supported by the Ministry of Science and Technology (MOST) in Taiwan under the Grant MOST 109-2221-E-197-001-MY2 and the Czech Science Foundation in Czech Republic under the project No. 19-11516S.

\section{Conflicts of Interest}

The authors declare no conflict of interest. 


\section{References}

[1] B. L. de Sena Costa, J. C. de Oliveira Freitas, P. H. S. Santos, D. M. de Araújo Melo, R. G. da Silva Araujo, and Y. H. de Oliveira, "Carbonation in Oil Well Portland Cement: Influence of Hydration Time Prior to Contact with CO2," Construction and Building Materials, vol. 159, pp. 252-260, January 2018.

[2] W. T. Lin, T. L. Weng, A. Cheng, S. J. Chao, and H. M. Hsu, "Properties of Controlled Low Strength Material with Circulating Fluidized Bed Combustion Ash and Recycled Aggregates," Materials, vol. 11, no. 5, 715, May 2018.

[3] H. L. Ho, R. Huang, L. C. Hwang, W. T. Lin, and H. M. Hsu, "Waste-Based Pervious Concrete for Climate-Resilient Pavements," Materials, vol. 11, no. 6, 900, May 2018.

[4] W. T. Lin, K. Korniejenko, M. Hebda, M. Łach, and J. Mikuła, "Engineering Properties of Ternary Cementless Blended Materials," International Journal of Engineering and Technology Innovation, vol. 10, no. 3, pp. 191-199, July 2020.

[5] V. M. Malhotra and P. K. Mehta, "High-Performance, High-Volume Fly Ash Concrete: Materials, Mixture Proportioning, Properties, Construction Practice, and Case Histories," Ottawa: Canadá, 2002.

[6] J. Damtoft, J. Lukasik, D. Herfort, D. Sorrentino, and E. Gartner, "Sustainable Development and Climate Change Initiatives," Cement and Concrete Research, vol. 38, pp. 115-127, February 2008.

[7] R. V. Upadhyaya and T. G. Suntharavadivel, "Optimization of Fly Ash and Metakaolin Content in Mineral Based CFRP Retrofit for Improved Sustainability,” International Journal of Engineering and Technology Innovation, vol. 9, no. 3, pp. 171-181, May 2019.

[8] M. Ali, R. Saidur, and M. S. Hossain, “A Review on Emission Analysis in Cement Industries," Renewable and Sustainable Energy Reviews, vol. 15, no. 5, pp. 2252-2261, June 2011.

[9] A. Hasan, M. G. Kibria, and F. M. Hasan, "Effects of Incorporating Recycled Brick and Stone Aggregate as Replacement of Natural Stone Aggregate in Concrete," International Journal of Engineering and Technology Innovation, vol. 9, no. 1, pp. 38-48, January 2019.

[10] K. Korniejenko, W. T. Lin, and H. Šimonová, "Mechanical Properties of Short Polymer Fiber-Reinforced Geopolymer Composites," Journal of Composites Science, vol. 4, no. 3, 128, September 2020.

[11] K. Korniejenko, M. Łach, S. Y. Chou, W. T. Lin, A. Cheng, M. Hebdowska-Krupa, et al., "Mechanical Properties of Short Fiber-Reinforced Geopolymers Made by Casted and 3D Printing Methods: A Comparative Study," Materials, vol. 13, no. 3, 579, January 2020.

[12] A. Workiye and E. Woldsenbet, "Development of Maize Stalk Cellulose Fiber Reinforced Calcined Kaolinite Clay Geopolymer Composites," Proceedings of Engineering and Technology Innovation, vol. 16, pp. 30-38, August 2020.

[13] M. Łach, J. Mikuła, W. T. Lin, P. Bazan, B. Figiela, and K. Korniejenko, "Development and Characterization of Thermal Insulation Geopolymer Foams Based on Fly Ash," Proceedings of Engineering and Technology Innovation, vol. 16, pp. 23-29, August 2020.

[14] M. Albitar, M. M. Ali, P. Visintin, and M. Drechsler, "Durability Evaluation of Geopolymer and Conventional Concretes," Construction and Building Materials, vol. 136, pp. 374-385, April 2017.

[15] R. Bajpai, K. Choudhary, A. Srivastava, K. S. Sangwan, and M. Singh, "Environmental Impact Assessment of Fly Ash and Silica Fume Based Geopolymer Concrete," Journal of Cleaner Production, vol. 254, 120147, May 2020.

[16] A. H. Sevinç and M. Y. Durgun, "Properties of High-Calcium Fly Ash-Based Geopolymer Concretes Improved with High-Silica Sources," Construction and Building Materials, vol. 261, 120014, November 2020.

[17] M. Xia and J. G. Sanjayan, "Methods of Enhancing Strength of Geopolymer Produced from Powder Based 3D Printing Process," Materials Letters, vol. 227, pp. 281-283, September 2018.

[18] S. Tuntachon, K. Kamwilaisak, T. Somdee, W. Mongkoltanaruk, V. Sata, K. Boonserm, et al., "Resistance to Algae and Fungi Formation of High Calcium Fly Ash Geopolymer Paste Containing TiO2," Journal of Building Engineering, vol. 25, 100817, September 2019.

[19] W. T. Lin, "Reactive Ultra-Fine Fly Ash as an Additive for Cement-Based Materials," Materials Today Communications, vol. 25, 101466, December 2020.

[20] S. Sasui, G. Kim, J. Nam, T. Koyama, and S. Chansomsak, "Strength and Microstructure of Class-C Fly Ash and GGBS Blend Geopolymer Activated in $\mathrm{NaOH} \& \mathrm{NaOH}+\mathrm{Na} 2 \mathrm{SiO} 3$," Materials, vol. 13, 59, January 2020.

[21] S. Samantasinghar and S. P. Singh, "Fresh and Hardened Properties of Fly Ash-Slag Blended Geopolymer Paste and Mortar," International Journal of Concrete Structures and Materials, vol. 13, no. 1, 47, December 2019.

[22] C. Tennakoon, P. De Silva, K. Sagoe-Crentsil, and J. G. Sanjayan, "Influence and Role of Feedstock Si and Al Content in Geopolymer Synthesis," Journal of Sustainable Cement-Based Materials, vol. 4, no. 2, pp. 129-139, January 2015. 
[23] N. T. Sithole and T. Mashifana, "Geosynthesis of Building and Construction Materials through Alkaline Activation of Granulated Blast Furnace Slag,” Construction and Building Materials, vol. 264, 20, December 2020.

[24] P. He, M. Wang, S. Fu, D. Jia, S. Yan, and J. Yuan, "Effects of Si/Al Ratio on the Structure and Properties of Metakaolin Based Geopolymer," Ceramics International, vol. 42, no. 13, pp. 14416-14422, October 2016.

[25] A. De Rossi, L. Simão, M. J. Ribeiro, D. Hotza, and R. D. F. P. M. Moreira, "Study of Cure Conditions Effect on the Properties of Wood Biomass Fly Ash Geopolymers," Journal of Materials Research and Technology, vol. 9, no. 4, pp. 7518-7528, July 2020.

[26] X. Guo, H. Shi, and W. A. Dick, "Compressive Strength and Microstructural Characteristics of Class C Fly Ash Geopolymer," Cement and Concrete Composites, vol. 32, no. 2, pp. 142-147, February 2010.

[27] E. Haq, S. K. Padmanabhan, and A. Licciulli, "Synthesis and Characteristics of Fly Ash and Bottom Ash Based Geopolymers-A Comparative Study,” Ceramics International, vol. 40, no. 2, pp. 2965-2971, March 2014.

[28] M. Heikal, M. Y. Nassar, G. El-Sayed, and S. M. Ibrahim, "Physico-Chemical, Mechanical, Microstructure and Durability Characteristics of Alkali Activated Egyptian Slag," Construction and Building Materials, vol. 69, pp. 60-72, October 2014.

[29] P. Prochon, Z. Zhao, L. Courard, T. Piotrowski, F. Michel, and A. Garbacz, "Influence of Activators on Mechanical Properties of Modified Fly Ash Based Geopolymer Mortars," Materials, vol. 13, 1033, February 2020.

[30] I. Gregora, N. Magneron, P. Simon, Y. Luspin, N. Raimboux, and E. Philippot, "Raman Study of AlPO4 (Berlinite) at the $\alpha-\beta$ Transition," Journal of Physics Condensed Matter, vol. 15, no. 25, pp. 4487-4501, June 2003.

[31] J. J. Leidy, F. E. Nieves, G. Silviany, S. P. Mariana de, Z. V. Erick, and M. B. Adriano, "Use of Fly and Bottom Ashes from a Thermoelectrical Plant in the Synthesis of Geopolymers: Evaluation of Reaction Efficiency," Energy Geoscience, vol. 2, no. 2, pp. 167-173, April 2021.

Copyright $($ by the authors. Licensee TAETI, Taiwan. This article is an open access article distributed under the terms and conditions of the Creative Commons Attribution (CC BY-NC) license (https://creativecommons.org/licenses/by-nc/4.0/). 